\title{
Pericardial Diseases in COVID19: a Contemporary Review
}

\author{
Muhammad M. Furqan ${ }^{1} \cdot$ Beni R. Verma ${ }^{1} \cdot$ Paul C. Cremer $^{1} \cdot$ Massimo Imazio $^{2} \cdot$ Allan L. Klein $^{1}$ (D)
}

Accepted: 15 April 2021 / Published online: 3 June 2021

(C) The Author(s), under exclusive licence to Springer Science+Business Media, LLC, part of Springer Nature 2021

\begin{abstract}
Purpose of Review Coronavirus disease 2019 (COVID19) involves the heart, including pericardium. This article reviews the possible pathophysiological mechanisms in pericardial involvement in COVID19 and pericardial manifestations of COVID19. It also summarizes the patients with pericarditis secondary to COVID19 and outlines the contemporary treatment strategies in this patient population. Recent Findings A high degree of suspicion is required to identify the pericardial involvement in COVID19 patients. It is proposed that an underlying hyperinflammatory reaction in COVID19 leads to pericardial inflammation. Acute pericarditis with or without myocardial involvement is diagnosed on clinical presentation, serum inflammatory markers, electrocardiogram, and echocardiogram. Multimodality imaging may also have an additional diagnostic value. Patients are usually managed medically, but some patients develop a life-threatening pericardial tamponade necessitating pericardial drainage.

Summary Pericardial involvement is an important clinical manifestation of COVID19 requiring a proper workup. Timely diagnosis and a specific management plan based on the presentation and concomitant organ involvement usually lead to a complete recovery.
\end{abstract}

Keywords Pericardial disease $\cdot$ Pericardial effusion $\cdot$ Pericarditis $\cdot$ Myocarditis $\cdot$ Pericardial tamponade $\cdot$ COVID19

\section{Introduction}

Coronavirus disease 2019 (COVID19) has infected more than 80 million people worldwide and caused more than 1.5 million deaths in 2020 [1]. Severe acute respiratory syndrome coronavirus 2 (SARS-CoV-2) is a novel coronavirus that causes COVID19. COVID19 primarily affects the lungs, and the

This article is part of the Topical Collection on Pericardial Disease

Allan L. Klein

kleina@ccf.org

Muhammad M. Furqan

furqanm@ccf.org

Beni R. Verma

vermab@ccf.org

Paul C. Cremer

cremerp@ccf.org

1 Center for the Diagnosis and Treatment of Pericardial Diseases, Section of Cardiovascular Imaging, Department of Cardiovascular Medicine, Heart, Vascular, and Thoracic Institute, Cleveland Clinic, Cleveland, OH, USA

2 Cardiothoracic Department, University Hospital "Santa Maria della Misericordia", Azienda Sanitaria Universitaria del Friuli Centrale (ASUFC), Piazzale Santa Maria della Misericordia 15, 33100 Udine, Italy severity of the disease ranges from mild respiratory symptoms to acute respiratory distress syndrome [2]. There is growing literature on the involvement of other organs, mainly the heart, kidneys, gastrointestinal tract, brain, and skin [3, 4]. Cardiac manifestations of COVID19 include acute heart failure, myocarditis, acute coronary syndrome, Takotsubo cardiomyopathy, arrhythmias, pericardial involvement, and cardiac arrest [5-7]. Pericardial diseases typically caused by viruses include pericarditis, pericardial effusion, and life-threatening pericardial tamponade (PT). A few cases of pericardial involvement in patients infected with other members of the coronavirus family have also been reported $[8,9,10]$. As the body of literature is expanding for COVID19, it is essential to understand some uncommon manifestations of the SARS-CoV-2 virus that require a high degree of suspicion. This review aims to identify COVID19-associated pericardial disease and briefly describe the underlying pathophysiological mechanisms. We have also summarized management strategies for COVID-19 associated pericardial diseases.

\section{Pathophysiologic Mechanisms}

The pericardium is a double-layered protective membrane around the heart with an inner visceral (serosal) and outer parietal (fibrous) layer. The pericardial sac between these 
two layers usually contains around 50cc of serous fluid [11]. The pericardium is relatively avascular, and increased vascularity is the hallmark of inflammation [12]. COVID19 is primarily a disease of respiratory epithelium, and endothelial cells play a crucial role in the involvement of other organs, including the heart [13•]. The exact pathophysiological mechanism of pericardial involvement in patients with COVID-19 has not been fully elucidated. At present, there is no evidence of direct infection of the pericardium and myocardium by SARS-Cov2. However, it is proposed that systemic inflammatory reaction induced by SARS-CoV-2 leads to cardiac involvement, including pericarditis. Endothelial damage as a result of heightened inflammation may also be responsible for pericardial manifestations. Although SARS-CoV-2 has also shown cardiotropic properties, the direct damage to the cardiac structures is rare (Fig. 1).

\section{COVID-19 mediated increased inflammation}

The levels of various inflammatory markers and cytokines are elevated in COVID19 infection. The hyperinflammatory syndrome in COVID19 is characterized by increased interleukins (IL-1, IL-2, IL-6, IL-7), granulocyte-macrophage colonystimulating factor, interferon- $\gamma$, inducible protein 10 , monocyte chemoattractant protein 1 , macrophage inflammatory protein 1- $\alpha$, and tumor necrosis factor (TNF)- $\alpha$ [14]. In a
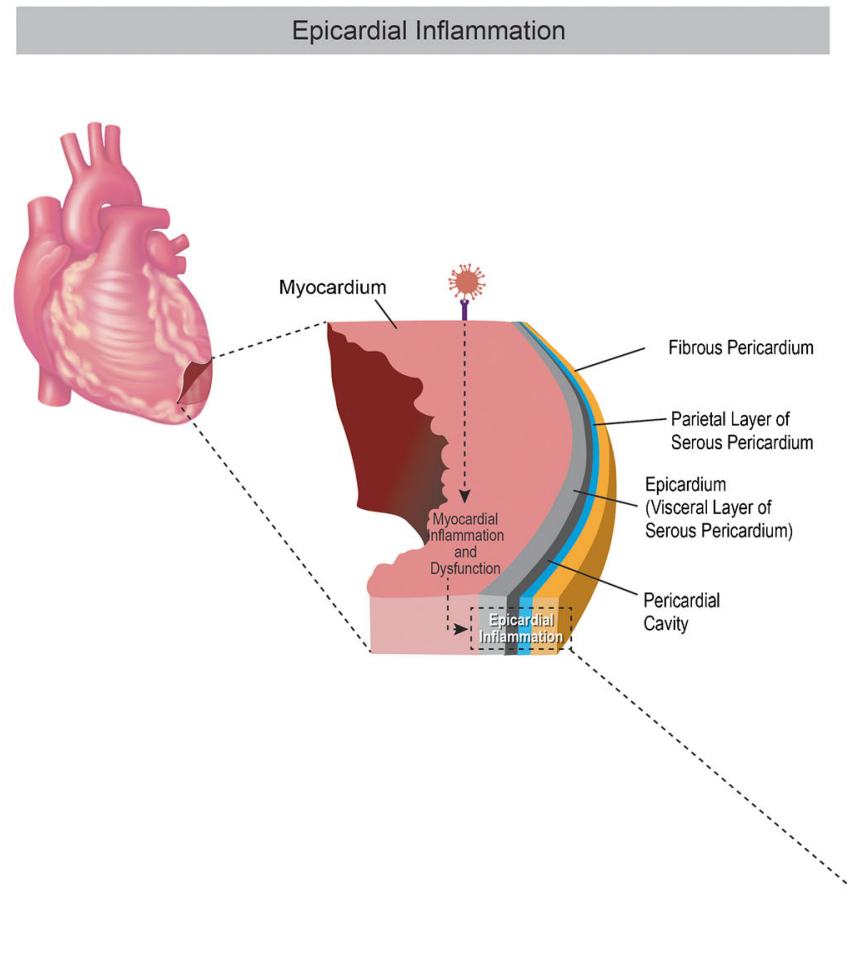

Fig. 1 Mechanisms of pericardial inflammation caused by SARS-CoV2. SARS-CoV2, severe acute respiratory syndrome coronavirus 2; ACE 2, angiotensin-converting enzyme; ILs, interleukins. (Reprinted with multicenter retrospective study, elevated IL6 and ferritin levels in COVID19 patients were associated with mortality [15]. This suggests hyper-inflammation and mortality associated with the systemic effects of inflammation in a subset of COVID19 patients. A cytokine storm is defined as an activation of an auto-amplifying cascade of cytokines due to unregulated host immune response to various triggers. This socalled cytokine storm is triggered by damage-associated molecular patterns and pathogen-associated molecular patterns, including infections, malignancy, autoimmune diseases, and drugs [16]. These triggers cause an imbalance of type 1 and type $2 \mathrm{~T}$ helper cells resulting in a hyperinflammatory response that causes a multi-organ involvement, including the heart in COVID19 patients [17]. The main mechanisms by which this heightened inflammation causes end-organ damage are mainly endothelial dysfunction, systemic cytokine circulation, and T-cell mediated immunopathology [18].

A recent study also found the activation of NLRP3 inflammasome in moderate and severe COVID19 cases [19]. Neutrophils and C-reactive protein are also significantly higher in severe cases $[2,20]$. Similarly, higher levels of proinflammatory cytokines such as IL-6, IL1-B, IL-2, IL8, IL17, G-CSF, GM-CSF, IP10, MCP1, MIP1a, and TNF are seen more frequently in symptomatic COVID19 patients with severe cases as compared to the moderately ill patients [20] [21]. Higher levels of inflammatory markers and cytokines are also
Microvascular Dysfunction

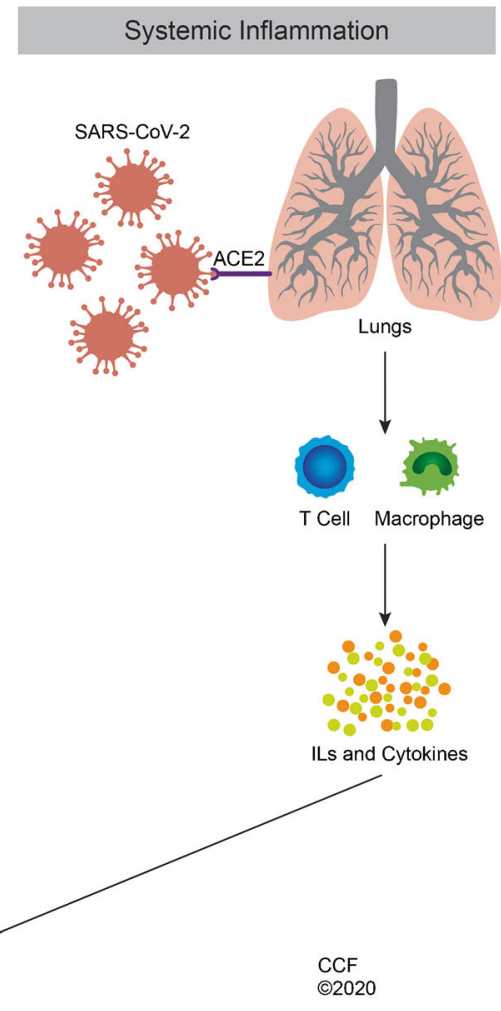

permission, Cleveland Clinic Center for Medical Arts and Photography (C)2020. All rights reserved.) 
associated with poor prognosis in COVID19 [22, 23]. Chemokines such as CXCL10 and CCL2 are found in the bronchoalveolar lavage fluid cells of patients with SARSCoV-2 infection [24]. Immunohistochemical endomyocardial biopsy (EMB) analysis of COVID19 patients revealed a high number of T-cells, macrophages, lymphocytes, T-memory cells, and cell adhesion molecules (CD54/ICAM-1). It also showed vascular damage and obliteration, leading to myocardial necrosis [25 $]$. Pericardial biopsy of a COVID19 positive patient showed reactive mesothelial cells, lymphocytes, and macrophages [26]. Postmortem histopathological analysis of the heart in patients who died of COVID19 also showed lymphocytic proliferation in the pericardium mainly composed of CD8+ lymphocytes within the visceral epicardium [27]. Cytokines such as IL1 and TNF- $\alpha$ are well established in the pathogenesis of pericarditis. The elevated levels of these interleukins in the activated inflammatory cascade setting predispose to pericardial inflammation [28]. The current evidence suggests that in addition to other organs, systemic inflammation may also involve the pericardium.

\section{Cardiac tropism of SARS-Cov2}

Histopathological analysis in a patient who died from COVID19 multi-inflammatory syndrome showed the infiltration of inflammatory cells in the pericardium. The inflammation was composed primarily of macrophages with a few lymphocytes and neutrophils. Viruses were identified from capillary endothelial cells and endocardial cells. Viral particles were also found in macrophages, neutrophils, and fibroblasts [29]. Tavazzi and colleagues showed SARS-CoV-2 particles in the interstitial macrophages, but not in cardiomyocytes [30]. A post-mortem analysis detected SARS-CoV-2 RNA in the heart samples of $82 \%$ of patients who died of COVID19, but no myocardial injury was found [31]. SARS-CoV-2 genome was present in 5\% of patients with suspected myocarditis or unexplained heart failure. Myocardium also had inflammatory cells, increased expression of cell adhesion molecules (CD34/ICAM-1), and myocardial necrosis [25•]. The virus was also identified from the pericardial fluid of a patient with COVID19 [32]. Angiotensin-converting enzyme-2 (ACE2) receptors are considered the main portals of entry by which SARS-CoV-2 enters the organs. ACE2 is also present in the heart, endothelium, cardiomyocytes, and epicardial adipose tissue adjacent to the visceral pericardium [33-35]. The presence of the virus in the cardiac endothelial cells indicates that SARS$\mathrm{CoV} 2$ can render direct damage to cardiac structures. The extent and exact pathways by which the virus potentially causes this direct damage to cardiac structures will need further exploration (Fig. 1).

\section{COVID-19 Associated Pericardial Involvement}

\section{Pericarditis}

The exact incidence of pericarditis in COVID19 patients is unknown, but the risk of pericardial involvement is higher in patients with clinical suspicion of COVID19 than in the general population [36]. Post-mortem studies have identified pericarditis in about $20 \%$ of the COVID19 cases [27, 37•]. Cardiac magnetic resonance imaging (CMR) of recently recovered COVID19 patients showed pericardial LGE in $22 \%$ of patients [38••]. In athletes recovering from COVID19 disease, $40 \%$ had pericardial late gadolinium enhancement (LGE), and $58 \%$ had pericardial effusions identified on CMR [39॰0]. Chest pain was positive in $29 \%$ of the healthcare workers infected with SARS-CoV2 at baseline, and they were evaluated for the presence of pericarditis and myocarditis after 10 weeks of viral infection. Only 19\% of the participants had persistent chest pain, and $14 \%$ of the total participants fulfilled the pericarditis criteria at week 10 . Around $37 \%$ of these healthcare workers were also diagnosed with myocarditis based on the CMR criteria [40••].

Pericarditis in COVID19 presents with chest pain and viral symptoms [41, 42]. Some pericarditis patients may not have chest pain even with an associated myocarditis [43]. Many acute pericarditis cases also had a large pericardial effusion necessitating pericardial drainage [26, 42, 44-47]. Recently, many case reports have identified acute pericarditis in COVID19 patients without myocardial involvement. A synopsis of studies reporting acute pericarditis secondary to COVID19 disease is described in Table 1.

\section{Pericardial Effusion and Tamponade}

Pericardial effusion is found in 5\% of patients with coronavirus disease on chest computed tomography (CT) [55]. Pericardial effusion develops as a result of various insults to the myocardium or pericardium and has variable clinical presentations. Pericardial tamponade was identified in COVID19 patients with deteriorating renal and respiratory function [56, 57]. Pericardial tamponade in the setting of acute pericarditis in COVID19 patients is managed with pericardiocentesis, and occasionally a pericardial window is also required (Table 1).

A patient also developed pericardial tamponade after myocardial infarction. Interestingly, SARS-CoV-2 ribonucleic acid (RNA) was found in the pericardial fluid, but patient's nasopharyngeal analysis was negative for the virus [32]. Pericardial analysis of another patient with COVID19-associated polyserositis also detected SARSCoV-2 in the pericardial fluid [48]. However, other case reports evaluating pericardial effusions have not found any viral RNA in the pericardial fluid $[45,57,58]$. 


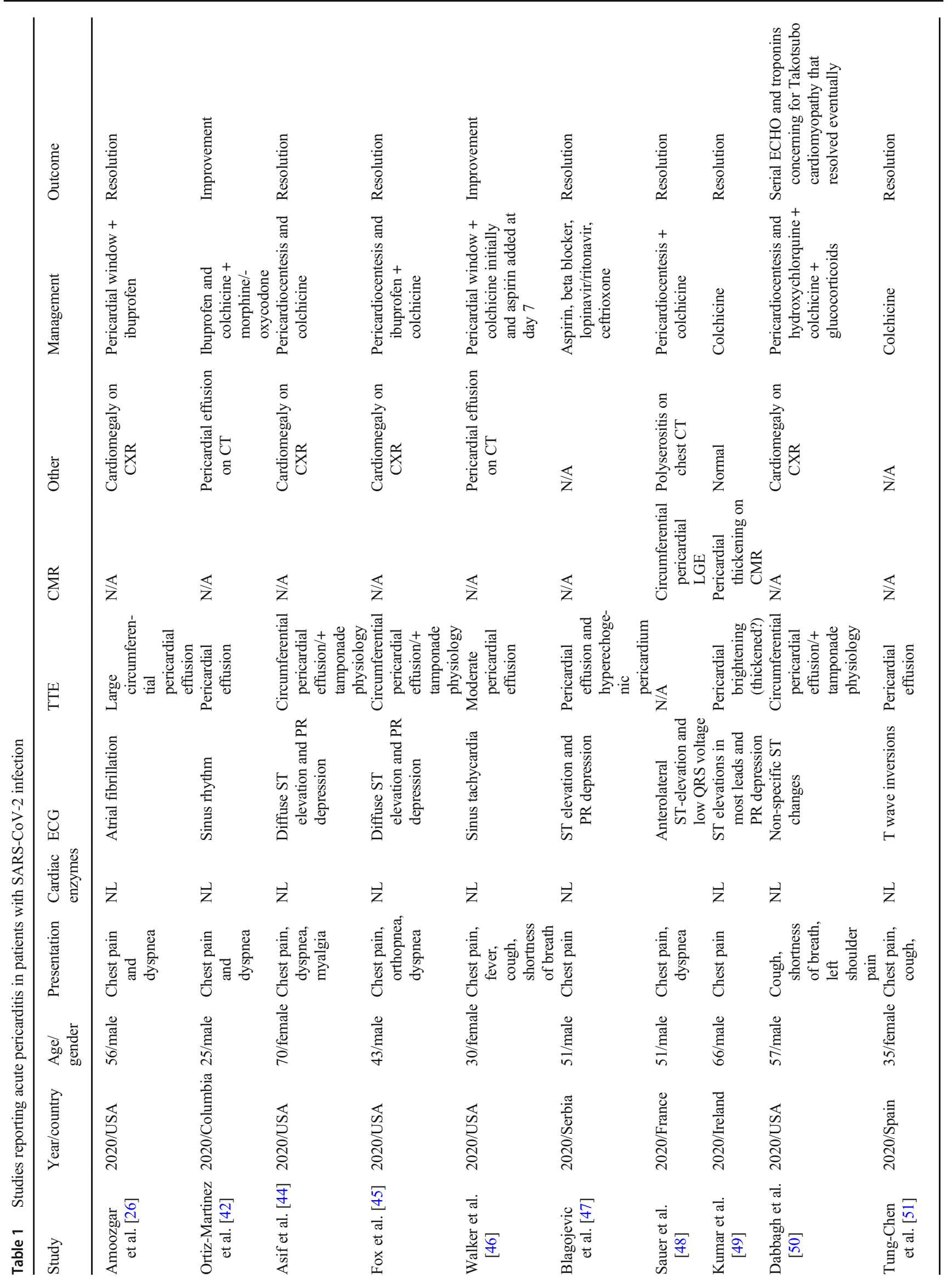




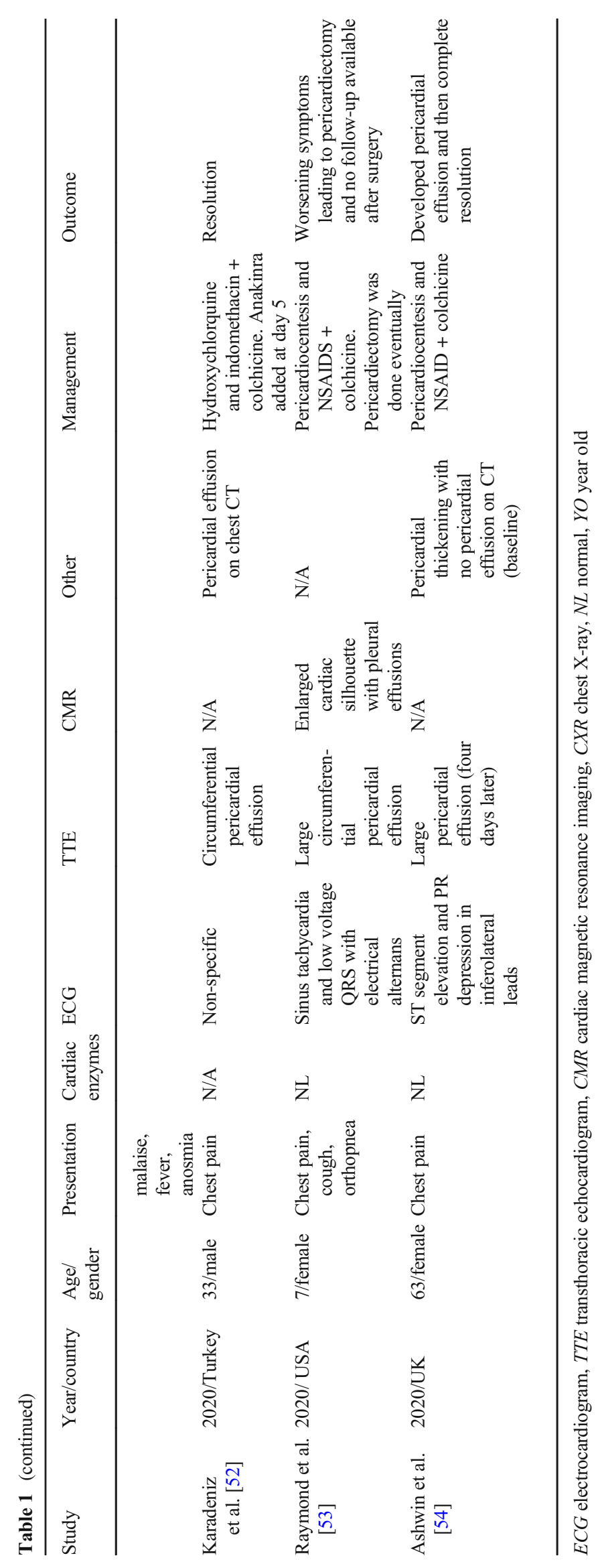




\section{Myopericarditis}

Acute cardiac injury is found in 7\%-17\% of COVID19 patients, and mortality is higher in the patients with cardiac injury $[2,59,60]$. Concomitant pericardial inflammation in patients with myocardial injury is also reported [29, 61]. COVID19-associated myopericarditis may present with or without respiratory tract symptoms [43, 62]. Chest pain is a common symptom, but some patients do not report chest pain and pose a diagnostic challenge [48, 63, 64]. Myopericarditis can also lead to cardiogenic shock and may require extracorporeal membrane oxygenation support and a left ventricular assist device for cardiac failure [65]. In a patient with myopericarditis associated with COVID19, a life-threatening cardiac tamponade was managed with pericardiocentesis [66]. Another severe case of myopericarditis was treated with intravenous immunoglobulin and methylprednisolone [67].

\section{Diagnosis of Pericardial Involvement in COVID19}

The suspicion of pericarditis must be high in patients experiencing symptoms of chest pain or raised inflammatory markers. A chest $\mathrm{x}$-ray (CXR) shows an enlarged cardiac silhouette in patients with moderate to severe pericardial effusion. An electrocardiogram (ECG) may show diffuse ST-segment elevation and PR depressions, especially with concomitant myocardial involvement. However, a normal ECG does not exclude the diagnosis, and an echocardiogram may yield important information such as the presence of pericardial effusion and its hemodynamic impact [68]. Multimodality imaging, including CMR and CT scan, can show the pericardial inflammation and edema in addition to the pericardial effusion [69]. A case series of COVID19associated pericardial diseases used a multimodality imagingbased approach to diagnose the pericardial conditions accurately [48]. Pulmonary embolism should be in the differential diagnosis of COVID19 due to an increased prothrombotic risk. These patients also develop pleuritic left-sided chest pain.

Several COVID19 patients with pericarditis had typical ECG changes associated with pericardial inflammation. Most of these patients had an enlarged cardiac silhouette on CXR, and echocardiography usually confirmed pericardial effusion (Table 1).

\section{Management of pericardial involvement in COVID19}

\section{Anti-Inflammatory Therapies in Pericardial Diseases}

The mainstay for the treatment of acute and recurrent pericarditis is NSAIDs and colchicine. Corticosteroids are used in cases of treatment failure, resistance, or contraindications to first-line therapy [68]. IL1 receptor antagonists (anakinra and rilonacept), intravenous immunoglobulins, and azathioprine are recommended in refractory recurrent pericarditis patients $[70 \bullet \bullet, 71 \bullet \cdot$. Some additional drugs such as azathioprine and intravenous immunoglobulins are also used in selected refractory cases [72, 73].

\section{Safety of Anti-Inflammatory Drugs in COVID19}

The safety of NSAIDs in COVID19 patients was questioned after reports of worsening symptoms in a few patients [74]. Ibuprofen is linked to an increased expression of ACE2 receptors, but this does not establish any causative link to the severity of symptoms and warrants further investigation [75]. Observational studies on the use of aspirin in COVID19 patients have shown conflicting results. Chow et al. [76] reported decreased mortality, ICU admission, and mechanical ventilation, but Sahai et al. [77] found no change in mortality and an increased thrombotic risk in COVID19 patients taking aspirin. Current World Health Organization and Food and Drug Administration guidelines do not recommend stopping NSAIDs in symptomatic COVID19 patients [78, 79]. Recurrent pericarditis patients usually taper the antiinflammatory drugs slowly over several months and are at risk of flare if anti-inflammatory drugs, such as NSAIDs, are stopped abruptly [80]. Colchicine is also safe to use in COVID19 patients and is currently explored as a potential treatment for COVID19. Various randomized trials have established on colchicine's safety and efficacy in the early phases of COVID19 and show that it may also decrease complications and mortality $[81 \bullet, 82,83 \bullet \bullet$. Corticosteroids are recommended for severe or complicated COVID19 cases or concomitant disease with specific indications for steroids [84]. Moreover, anakinra (an IL1 receptor antagonist) is also used safely in COVID19 patients [70••] [85].

\section{Patients with Established Pericarditis Developing COVID19}

Patients with pericarditis (acute or recurrent) developing mild to moderate COVID19 may continue their NSAIDs and colchicine for pericardial inflammation. Recurrent pericarditis patients may also continue to use corticosteroids and anakinra. Continuous monitoring is warranted in all patients taking corticosteroids or anakinra; however, these treatments are also potential therapies for COVID-19 [86].

\section{COVID19 Patients Developing Pericarditis}

There is no concrete evidence on the management of COVID19-associated pericarditis. Physicians usually avoid the use of aspirin, but ibuprofen and colchicine are considered safe. Corticosteroids may also be used in COVID19-associated pericarditis, as dexamethasone has also been shown to improve mortality and increased ventilator-free days in COVID19 [87]. 
There are a few cases of successful use of anakinra in COVID19 pericarditis [52]. In our review of literature, the majority of COVID19-associated acute pericarditis cases were treated with colchicine and NSAIDs. Corticosteroids were also added in complicated cases (Table 1).

\section{Future Directions}

The current evidence shows that pericardial involvement is an important clinical manifestation of COVID19, requiring a proper workup and a specific management plan based on the presentation and concomitant organ involvement. Most pericarditis treatments (e.g., colchicine, corticosteroids, and anakinra) are safe and efficacious also for COVID-19. Further studies evaluating the incidence and pathophysiology of pericardial diseases in COVID19 patients will help understand the disease burden and refine appropriate treatment strategies.

Abbreviations COVID19, Coronavirus disease 2019; SARS-CoV-2, Severe acute respiratory syndrome coronavirus-2; RNA, Ribonucleic acid; PT, Pericardial tamponade; IL, Interleukin; TNF, Tumor necrosis factor; ACE2, Angiotensin-converting enzyme-2; ECG, Electrocardiogram; CMR, Cardiac magnetic resonance; LGE, Late gadolinium enhancement; CT, Computed tomography; NSAID, Non-steroidal anti-inflammatory drug

\section{Declarations}

Conflict of Interest Muhammad M. Furqan and Beni R. Verma and declare that they have no conflict of interest.

Paul C. Cremer reports grants and personal fees from Kiniksa Pharmaceuticals, and grants from Novartis Pharmaceuticals.

Massimo Imazio has been on Advisory Board for Sobi and Kiniksa Pharmaceuticals.

Allan L. Klein receives honorarium from Sobi and Pfizer Pharmaceuticals. Also, he receives a research grant from Kiniksa Pharmaceuticals.

Human and Animal Rights and Informed Consent This article does not contain any studies with human or animal subjects performed by any of the authors.

\section{References}

Papers of particular interest, published recently, have been highlighted as:

- Of importance

•- Of major importance

1. WHO Coronavirus Disease (COVID-19) Dashboard | WHO Coronavirus Disease (COVID-19) Dashboard. Available at: https://covid19.who.int/. Accessed January 11, 2021.
2. Wang D, Hu B, Hu C, Zhu F, Liu X, Zhang J, et al. Clinical characteristics of 138 hospitalized patients with 2019 novel coronavirus-infected pneumonia in Wuhan, China. JAMA - J Am Med Assoc. 2020;323(11):1061-9. https://doi.org/10.1001/jama. 2020.1585.

3. Chen N, Zhou M, Dong X, Qu J, Gong F, Han Y, et al. Epidemiological and clinical characteristics of 99 cases of 2019 novel coronavirus pneumonia in Wuhan, China: a descriptive study. Lancet. 2020;395(10223):507-13. https://doi.org/10.1016/ S0140-6736(20)30211-7.

4. Mawhirt SL, Frankel D, Diaz AM. Cutaneous manifestations in adult patients with COVID-19 and dermatologic conditions related to the COVID-19 pandemic in health care workers. Curr Allergy Asthma Rep. 2020;20:75. https://doi.org/10.1007/s11882-02000974-w.

5. Jabri A, Kalra A, Kumar A, Alameh A, Adroja S, Bashir H, et al. Incidence of stress cardiomyopathy during the coronavirus disease 2019 pandemic. JAMA Netw Open. 2020;3(7):e2014780. https:// doi.org/10.1001/jamanetworkopen.2020.14780.

6. Zou F, Qian Z, Wang Y, Zhao Y, Bai J. Cardiac injury and COVID19: a systematic review and meta-analysis. CJC Open. 2020;2:38694. https://doi.org/10.1016/j.cjco.2020.06.010.

7. Malaty M, Kayes T, Amarasekera AT, Kodsi M, MacIntyre CR, Tan TC. Incidence and treatment of arrhythmias secondary to coronavirus infection in humans: a systematic review. Eur J Clin Investig. 2020;51:e13428. https://doi.org/10.1111/eci.13428.

8. Cabeça TK, Bellei N. Human coronavirus NL-63 infection in a Brazilian patient suspected of H1N1 2009 influenza infection: Description of a fatal case. J Clin Virol. 2012;53(1):82-4. https:// doi.org/10.1016/j.jcv.2011.09.006.

9. Furqan MM, Lak HM, Mahalwar G, Abou-Hassan O, Verma BR, Jellis CL, Klein AL. Recurrent pericarditis associated with human coronavirus (HKU1) infection in a patient with systemic lupus erythematosus (SLE). Echocardiography 2021:echo.15062. Available at: https://doi.org/10.1111/echo.15062. Accessed May 10, 2021.

10. Al-Abdallat MM, Payne DC, Alqasrawi S, et al. Hospitalassociated outbreak of middle east respiratory syndrome coronavirus: a serologic, epidemiologic, and clinical description. Clin Infect Dis. 2014;59(9):1225-33. https://doi.org/10.1093/cid/ciu359.

11. Holt JP. The normal pericardium. Am J Cardiol. 1970;26(5):45565. https://doi.org/10.1016/0002-9149(70)90702-2.

12. Cremer PC, Kumar A, Kontzias A, Tan CD, Rodriguez ER, Imazio $\mathrm{M}$, et al. Complicated pericarditis: understanding risk factors and pathophysiology to inform imaging and treatment. J Am Coll Cardiol. 2016;68:2311-28. https://doi.org/10.1016/j.jacc.2016.07. 785.

13. Libby P, Lüscher T. COVID-19 is, in the end, an endothelial disease. Eur Heart J. 2020;41(32):3038-44. https://doi.org/10.1093/ eurheartj/ehaa623 Review article describing the systemic involvement of SARS-CoV-2.

14. Huang C, Wang Y, Li X, Ren L, Zhao J, Hu Y, et al. Clinical features of patients infected with 2019 novel coronavirus in Wuhan, China. Lancet. 2020;395(10223):497-506. https://doi. org/10.1016/S0140-6736(20)30183-5.

15. Ruan Q, Yang K, Wang W, Jiang L, Song J. Clinical predictors of mortality due to COVID-19 based on an analysis of data of 150 patients from Wuhan, China. Intensive Care Med. 2020;46:846-8. https://doi.org/10.1007/s00134-020-05991-x.

16. Tang Y, Liu J, Zhang D, Xu Z, Ji J, Wen C. Cytokine storm in COVID-19: the current evidence and treatment strategies. Front Immunol. 2020;11:1708. https://doi.org/10.3389/fimmu.2020. 01708.

17. Zheng YY, Ma YT, Zhang JY, Xie X. COVID-19 and the cardiovascular system. Nat Rev Cardiol. 2020;17:259-60. https://doi.org/ 10.1038/s41569-020-0360-5. 
18. Tisoncik JR, Korth MJ, Simmons CP, Farrar J, Martin TR, Katze MG. Into the eye of the cytokine storm. Microbiol Mol Biol Rev. 2012;76(1):16-32. https://doi.org/10.1128/mmbr.05015-11.

19. Rodrigues TS, de Sá KSG, Ishimoto AY, Becerra A, Oliveira S, Almeida L, et al. Inflammasomes are activated in response to SARS-CoV-2 infection and are associated with COVID-19 severity in patients. J Exp Med. 2021;218(3):e20201707. https://doi.org/10. 1084/jem.20201707.

20. Chen G, Wu D, Guo W, Cao Y, Huang D, Wang H, et al. Clinical and immunological features of severe and moderate coronavirus disease 2019. J Clin Invest. 2020;130(5):2620-9. https://doi.org/ 10.1172/JCI137244.

21. Cao X. COVID-19: immunopathology and its implications for therapy. Nat Rev Immunol. 2020;20:269-70. https://doi.org/10.1038/ s41577-020-0308-3.

22. Liu F, Li L, Da Xu M, et al. Prognostic value of interleukin-6, Creactive protein, and procalcitonin in patients with COVID-19. J Clin Virol. 2020;127:104370. https://doi.org/10.1016/j.jcv.2020. 104370.

23. Zeng F, Huang Y, Guo Y, Yin M, Chen X, Xiao L, et al. Association of inflammatory markers with the severity of COVID-19: A meta-analysis. Int J Infect Dis. 2020;96:467-74. https://doi.org/10.1016/j.ijid.2020.05.055.

24. Xiong Y, Liu Y, Cao L, Wang D, Guo M, Jiang A, et al. Transcriptomic characteristics of bronchoalveolar lavage fluid and peripheral blood mononuclear cells in COVID-19 patients. Emerg Microbes Infect. 2020;9(1):761-70. https://doi.org/10.1080/ 22221751.2020 .1747363$.

25. Escher F, Pietsch H, Aleshcheva G, et al. Detection of viral SARSCoV-2 genomes and histopathological changes in endomyocardial biopsies. ESC Hear Fail. 2020. https://doi.org/10.1002/ehf2.12805 This articles describes the SARS-CoV-2 genome detection in the endomyocardial biopsies in suspected myocarditis or unexplained heart failure.

26. Amoozgar B, Kaushal V, Mubashar U, Sen S, Yousaf S, Yotsuya M. Symptomatic pericardial effusion in the setting of asymptomatic COVID-19 infection: a case report. Medicine (Baltimore). 2020;99(37):e22093. https://doi.org/10.1097/MD. 0000000000022093 .

27. Basso C, Leone O, Rizzo S, de Gaspari M, van der Wal AC, Aubry $\mathrm{MC}$, et al. Pathological features of COVID-19-associated myocardial injury: a multicentre cardiovascular pathology study. Eur Heart J. 2020;41:3827-35. https://doi.org/10.1093/eurheartj/ehaa664.

28. Lopalco G, Rigante D, Cantarini L, Imazio M, Lopalco A, Emmi G, et al. The autoinflammatory side of recurrent pericarditis: Enlightening the pathogenesis for a more rational treatment. Trends Cardiovasc Med. 2020. https://doi.org/10.1016/j.tcm.2020. 04.006 .

29. Dolhnikoff M, Ferreira FJ, de Almeida Monteiro RA, et al. SARSCoV-2 in cardiac tissue of a child with COVID-19-related multisystem inflammatory syndrome. Lancet Child Adolesc Health. 2020;4642(20):1-5. https://doi.org/10.1016/S2352-4642(20) 30257-1.

30. Tavazzi G, Pellegrini C, Maurelli M, Belliato M, Sciutti F, Bottazzi A, et al. Myocardial localization of coronavirus in COVID-19 cardiogenic shock. Eur J Heart Fail. 2020;22(5):911-5. https://doi.org/ 10.1002/ejhf.1828.

31. Remmelink M, De Mendonça R, D'Haene N, et al. Unspecific postmortem findings despite multiorgan viral spread in COVID-19 patients. Crit Care. 2020;24(1):495. https://doi.org/10.1186/s13054020-03218-5.

32. Farina A, Uccello G, Spreafico M, Bassanelli G, Savonitto S. SARS-CoV-2 detection in the pericardial fluid of a patient with cardiac tamponade. Eur J Intern Med. 2020;76:100-1. https://doi. org/10.1016/j.ejim.2020.04.045.
33. Danilczyk U, Penninger JM. Angiotensin-converting enzyme II in the heart and the kidney. Circ Res. 2006;98:463-71. https://doi.org/ 10.1161/01.RES.0000205761.22353.5f.

34. Tucker NR, Chaffin M, Bedi KC, et al. Myocyte-specific upregulation of ACE2 in cardiovascular disease: Implications for SARSCoV-2-mediated myocarditis. Circulation. 2020;142:708-10. https://doi.org/10.1161/CIRCULATIONAHA.120.047911.

35. Patel AB, Verma A. COVID-19 and angiotensin-converting enzyme inhibitors and angiotensin receptor blockers: what is the evidence? JAMA - J Am Med Assoc. 2020;323:1769-70. https://doi. org/10.1001/jama.2020.4812.

36. Miró Ò, Llorens P, Jiménez S, Piñera P, Burillo-Putze G, Martín A, et al. Frequency of five unusual presentations in patients with COVID-19: results of the UMC-19-S1. Epidemiol Infect. 2020;148:e189. https://doi.org/10.1017/S0950268820001910.

37. Hanley B, Naresh KN, Roufosse C, et al. Histopathological findings and viral tropism in UK patients with severe fatal COVID-19: a post-mortem study. Lancet Microbe. 2020;1(6):e245-53. https:// doi.org/10.1016/s2666-5247(20)30115-4 This paper describes the pericardial involvement in the post-mortem findings of patients with fatal COVID19.

38.• Puntmann VO, Carerj ML, Wieters I, et al. Outcomes of cardiovascular magnetic resonance imaging in patients recently recovered from coronavirus disease 2019 (COVID-19). JAMA Cardiol. 2020;2019:1-9. https://doi.org/10.1001/jamacardio.2020.3557 Prospective observational study demonstrating the long-term cardiovascular outcomes in patients who recovered from symptomatic COVID19.

39.• Brito D, Meester S, Yanamala N, et al. High prevalence of pericardial involvement in college student athletes recovering from COVID-19. JACC Cardiovasc Imaging. 2020. https://doi.org/10. 1016/j.jcmg.2020.10.023 This paper reports the prevalence of pericardial involvement and imaging findings in athletes.

40.• Eiros R, Barreiro-Perez M, Martin-Garcia A, et al. Pericarditis and myocarditis long after SARS-CoV-2 infection: a cross-sectional descriptive study in health-care workers. medrxiv. n.d.. https://doi. org/10.1101/2020.07.12.20151316 Descriptive study assessing the long-term effects of SARS-CoV2 infection on heart. It presents the prevalence of pericarditis, myocarditis, myopericarditis, and perimyocareditis in healthcare workers recovering from COVID19.

41. Kumar S, Paz D. Clinical case and assessment databases in periodontology created from virtual clinic rotation. J Dent Educ. 2020: jdd.12293. https://doi.org/10.1002/jdd.12293.

42. Ortiz-Martínez Y, Cabeza-Ruiz LD, Vásquez-Lozano SH, Villamil-Gómez WE, Rodriguez-Morales AJ. Pericarditis in a young internal medicine resident with COVID-19 in Colombia. Travel Med Infect Dis. 2020;37:101863. https://doi.org/10.1016/j. tmaid.2020.101863.

43. Purohit R, Kanwal A, Pandit A, et al. Acute myopericarditis with pericardial effusion and cardiac tamponade in a patient with COVID-19. Am J Case Rep. 2020;21:1-4. https://doi.org/10. 12659/AJCR.925554.

44. Asif T, Kassab K, Iskander F, Alyousef T. Acute pericarditis and cardiac tamponade in a patient with COVID-19: a therapeutic challenge. Eur J Case Reports Intern Med. 2020;7(6):001701. https:// doi.org/10.12890/2020_001701.

45. Fox K, Prokup JA, Butson K, Jordan K. Acute effusive pericarditis: a late complication of COVID-19. Cureus. 2020;12(7):e9074. https://doi.org/10.7759/cureus.9074.

46. Walker C, Peyko V, Farrell C, Awad-Spirtos J, Adamo M, Scrocco J. Pericardial effusion and cardiac tamponade requiring pericardial window in an otherwise healthy 30 -year-old patient with COVID19: a case report. J Med Case Rep. 2020;14(1):158. https://doi.org/ 10.1186/s13256-020-02467-w. 
47. Blagojevic NR, Bosnjakovic D, Vukomanovic V, Arsenovic S, Lazic JS, Tadic M. Acute pericarditis and severe acute respiratory syndrome coronavirus 2: case report. Int J Infect Dis. 2020;101: 180-2. https://doi.org/10.1016/j.ijid.2020.09.1440.

48. Sauer F, Dagrenat C, Couppie P, Jochum G, Leddet P. Pericardial effusion in patients with COVID-19: case series. Eur Hear J - Case Rep. 2020;4(FI1):1-7. https://doi.org/10.1093/ehjcr/ytaa287.

49. Kumar R, Kumar J, Daly C, Edroos SA. Acute pericarditis as a primary presentation of COVID-19. BMJ Case Rep. 2020;13(8): 1-3. https://doi.org/10.1136/bcr-2020-237617.

50. Dabbagh MF, Aurora L, D'Souza P, Weinmann AJ, Bhargava P, Basir MB. Cardiac tamponade secondary to COVID-19. JACC Case Rep. 2020;2(9):1326-30. https://doi.org/10.1016/j.jaccas. 2020.04.009.

51. Tung-Chen Y. Acute pericarditis due to COVID-19 infection: an underdiagnosed disease? Med Clin (Barc). 2020;155:44-5. https:// doi.org/10.1016/j.medcli.2020.04.007.

52. Karadeniz H, Yamak BA, Özger HS, Sezenöz B, Tufan A, Emmi G. Anakinra for the treatment of COVID-19-associated pericarditis: a case report. Cardiovasc Drugs Ther. 2020;34:883-5. https://doi. org/10.1007/s10557-020-07044-3.

53. Raymond TT, Das A, Manzuri S, Ehrett S, Guleserian K, Brenes J. Pediatric COVID-19 and pericarditis presenting with acute pericardial tamponade. World J Pediatr Congenit Heart Surg. 2020;11(6): 802-4. https://doi.org/10.1177/2150135120949455.

54. Reddy A, Nethercott S, Duehmke R, Nair S, Abdul-Samad O. 'Dry' pericarditis with rapid progression to tamponade as a feature of COVID-19. Eur Med J. 2021. https://doi.org/10.33590/emj/2000244.

55. Bao C, Liu X, Zhang H, Li Y, Liu J. Coronavirus disease 2019 (COVID-19) CT findings: a systematic review and meta-analysis. J Am Coll Radiol. 2020;17(6):701-9. https://doi.org/10.1016/j.jacr. 2020.03 .006

56. Naderi N, Ansari Ramandi MM, Baay M, et al. Cardiovascular patients in COVID-19 era, a case series, an experience from a tertiary cardiovascular center in Tehran, Iran. Clin Case Rep. 2020;(May):1-7. https://doi.org/10.1002/ccr3.3163.

57. Derveni V, Kaniaris E, Toumpanakis D, Potamianou E, Ioannidou I, Theodoulou D, et al. Acute life-threatening cardiac tamponade in a mechanically ventilated patient with COVID-19 pneumonia. IDCases. 2020;21:e00898. https://doi.org/10.1016/j.idcr.2020. e00898.

58. Allam HH, Kinsara AJ, Tuaima T, Alfakih S. Pericardial fluid in a COVID-19 patient: is it exudate or transudate? Eur J Case Reports Intern Med. 2020;7(6):001703. https://doi.org/10.12890/2020 001703.

59. Zhou F, Yu T, Du R, et al. Clinical course and risk factors for mortality of adult inpatients with COVID-19 in Wuhan, China: a retrospective cohort study. Lancet. 2020;395(10229):1054-62. https://doi.org/10.1016/S0140-6736(20)30566-3.

60. Shi S, Qin M, Shen B, Cai Y, Liu T, Yang F, et al. Association of cardiac injury with mortality in hospitalized patients with COVID19 in Wuhan, China. JAMA Cardiol. 2020;5(7):802-10. https://doi. org/10.1001/jamacardio.2020.0950.

61. Shah ZS, Kumar SA, Patel AA. Myocarditis and pericarditis in patients with COVID-19. Hear Views. 2020;21(3):209. https:// doi.org/10.4103/HEARTVIEWS.HEARTVIEWS_154_20.

62. Inciardi RM, Lupi L, Zaccone G, Italia L, Raffo M, Tomasoni D, et al. Cardiac involvement in a patient with coronavirus disease 2019 (COVID-19). JAMA Cardiol. 2019;2020(7):819-24. https:// doi.org/10.1001/jamacardio.2020.1096.

63. Cizgici AY, Zencirkiran AH, Yildiz M. COVID-19 myopericarditis: IT should be kept in mind in today's conditions. Am J Emerg Med. 2020;38(7):1547.e5-6. https://doi.org/10.1016/ j.ajem.2020.04.080.
64. Naneishvili T, Khalil A, O’Leary R, Prasad N. Fulminant myocarditis as an early presentation of SARS-CoV-2. BMJ Case Rep. 2020;13(9):e237553. https://doi.org/10.1136/bcr-2020-237553.

65. Newton-Cheh C, Zlotoff DA, Hung J, Rupasov A, Crowley JC, Funamoto M. Case 24-2020: A 44-year-old woman with chest pain, dyspnea, and shock. N Engl J Med. 2020;383(5):475-84. https:// doi.org/10.1056/NEJMcpc2004975.

66. Hua A, O'Gallagher K, Sado D, Byrne J. Life-threatening cardiac tamponade complicating myo-pericarditis in COVID-19. Eur Heart J. 2020;41(22):2130. https://doi.org/10.1093/eurheartj/ehaa253.

67. Li A, Garcia-Bengochea Y, Stechel R, Azari BM. Management of COVID-19 myopericarditis with reversal of cardiac dysfunction after blunting of cytokine storm: a case report. Eur Hear J - Case Rep. 2020;4(FI1):1-6. https://doi.org/10.1093/ehjcr/ytaa224.

68. Adler Y, Charron P, Imazio M, Badano L, Barón-Esquivias G, Bogaert J, et al. 2015 ESC Guidelines for the diagnosis and management of pericardial diseases. Eur Heart J. 2015;36(42):2921-64. https://doi.org/10.1093/eurheartj/ehv318.

69. Chetrit M, Xu B, Verma BR, Klein AL. Multimodality imaging for the assessment of pericardial diseases. Curr Cardiol Rep. 2019;21: 41. https://doi.org/10.1007/s11886-019-1115-y.

70.• Brucato A, Imazio M, Gattorno M, et al. Effect of anakinra on recurrent pericarditis among patients with colchicine resistance and corticosteroid dependence. JAMA. 2016;316(18):1906. https://doi.org/10.1001/jama.2016.15826 Randomized trial on the use of anakinra (Interleukin-1 receptor antagonist) in recurrent and resistant pericarditis.

71.• Klein A, Imazio M, Brucato A, et al. RHAPSODY: Rationale for and design of a pivotal phase 3 trial to assess efficacy and safety of rilonacept, an IL- $1 \alpha$ and IL- $1 \beta$ trap, in patients with recurrent pericarditis. Am Heart J. 2020;228:81-90. https://doi.org/10.1016/j.ahj. 2020.07.004 Randomized trial demonstrating the role of interleukin-1 inhibition in the treatement of recurrent pericarditis resistant to first and second-line therapy.

72. Imazio M, Lazaros G, Picardi E, Vasileiou P, Carraro M, Tousoulis $\mathrm{D}$, et al. Intravenous human immunoglobulins for refractory recurrent pericarditis. J Cardiovasc Med. 2016;17(4):263-9. https://doi. org/10.2459/JCM.0000000000000260.

73. Vianello F, Cinetto F, Cavraro M, Battisti A, Castelli M, Imbergamo S, et al. Azathioprine in isolated recurrent pericarditis: a single centre experience. Int J Cardiol. 2011;147(3):477-8. https://doi.org/10.1016/j.ijcard.2011.01.027.

74. Day M. Covid-19: ibuprofen should not be used for managing symptoms, say doctors and scientists. BMJ. 2020;368:m1086. https://doi.org/10.1136/bmj.m1086.

75. Sodhi M, Etminan M. Safety of ibuprofen in patients with COVID19: causal or confounded? Chest. 2020;158:55-6. https://doi.org/ 10.1016/j.chest.2020.03.040.

76. Chow JH, Khanna AK., Kethireddy S., et al. Aspirin use is associated with decreased mechanical ventilation, ICU admission, and inhospital mortality in hospitalized patients with COVID-19. vol. Publish Ah. 2020.

77. Sahai A, Bhandari R, Koupenova M, et al. SARS-CoV-2 Receptors are expressed on human platelets and the effect of aspirin on clinical outcomes in COVID-19 patients. Res Sq. n.d.. https://doi.org/10. 21203/RS.3.RS-119031/V1.

78. The use of non-steroidal anti-inflammatory drugs (NSAIDs) in patients with COVID-19. Available at: https://www.who.int/newsroom/commentaries/detail/the-use-of-non-steroidal-antiinflammatory-drugs-(nsaids)-in-patients-with-covid-19. Accessed October 26, 2020.

79. FDA advises patients on use of non-steroidal anti-inflammatory drugs (NSAIDs) for COVID-19 | FDA. Available at: https://www. fda.gov/drugs/drug-safety-and-availability/fda-advises-patientsuse-non-steroidal-anti-inflammatory-drugs-nsaids-covid-19. Accessed October 26, 2020. 
80. Lazaros G, Imazio M, Brucato A, Tousoulis D. Untying the Gordian knot of pericardial diseases: a pragmatic approach. Hell J Cardiol. 2016;57(5):315-22. https://doi.org/10.1016/j.hjc.2016.11. 024.

81. Lopes MI, Bonjorno LP, Giannini MC, et al. Beneficial effects of colchicine for moderate to severe COVID-19: an interim analysis of a randomized, double-blinded, placebo controlled clinical trial. MedRxiv. 2020:2020.08.06.20169573. https://doi.org/10.1101/ 2020.08.06.20169573 This interim report from a randomized control trial evaluates the beneficial role of colchicine in COVID19 patients.

82. Dalili N, Dalili N, Kashefizadeh A, et al. Adding colchicine to the antiretroviral medication-lopinavir/ritonavir (Kaletra) in hospitalized patients with non-severe Covid-19 pneumonia: a structured summary of a study protocol for a randomized controlled trial. Trials. 2020;21:489. https://doi.org/10.1186/s13063-020-04455-3.

83.•- Deftereos SG, Giannopoulos G, Vrachatis DA, et al. Effect of colchicine vs standard care on cardiac and inflammatory biomarkers and clinical outcomes in patients hospitalized with coronavirus disease 2019: the GRECCO-19 randomized clinical trial. JAMA Netw Open. 2020;3(6):e2013136. https://doi.org/10.1001/ jamanetworkopen.2020.13136 A randomized trial on the use of colchicine in COVID19 patients.
84. Lamontagne F, Agoritsas T, MacDonald H, et al. A living WHO guideline on drugs for covid-19. BMJ. 2020;370:m3379. https:// doi.org/10.1136/bmj.m3379.

85. Huet T, Beaussier H, Voisin O, Jouveshomme S, Dauriat G, Lazareth I, et al. Anakinra for severe forms of COVID-19: a cohort study. Lancet Rheumatol. 2020;2(7):e393-400. https://doi.org/10. 1016/S2665-9913(20)30164-8.

86. Imazio M, Brucato A, Lazaros G, Andreis A, Scarsi M, Klein A, et al. Anti-inflammatory therapies for pericardial diseases in the COVID-19 pandemic: safety and potentiality. J Cardiovasc Med. 2020;21(9):625-9. https://doi.org/10.2459/JCM. 0000000000001059 .

87. Tomazini BM, Maia IS, Cavalcanti AB, Berwanger O, Rosa RG, Veiga VC, et al. Effect of dexamethasone on days alive and ventilator-free in patients with moderate or severe acute respiratory distress syndrome and COVID-19: the CoDEX randomized clinical trial. JAMA - J Am Med Assoc. 2020;324(13):1307-16. https://doi. org/10.1001/jama.2020.17021.

Publisher's Note Springer Nature remains neutral with regard to jurisdictional claims in published maps and institutional affiliations. 